\title{
End-stage renal disease versus death in a Portuguese cohort of elderly patients: an approach using competing event analysis
}

\author{
Josefina Santos, ${ }^{1,2}$ Isabel Fonseca, ${ }^{1,2,3}$ Jorge Malheiro, ${ }^{1,2}$ Idalina Beirao, ${ }^{1,2}$ \\ Luisa Lobato, ${ }^{1,2}$ Pedro Oliveira, ${ }^{3,4}$ Antonio Cabrita ${ }^{1}$
}

\begin{abstract}
${ }^{1}$ Nephrology Department, Hospital de Santo António, Centro Hospitalar e Universitário do Porto (CHUP), Porto, Portugal ${ }^{2}$ Unit for Multidisciplinary Research in Biomedicine, Instituto de Ciências Biomédicas Abel Salazar Porto, Universidade do Porto, Porto, Portugal ${ }^{3}$ ISPUP5EPI Unit,

Universidade do Porto, Porto, Portugal

${ }^{4}$ Department of Population Studies, Instituto de Ciências Biomédicas Abel Salazar Porto, Universidade do Porto, Porto, Portugal
\end{abstract}

\section{Correspondence to} Josefina Santos, Nephrology Department, Hospital de Santo António, Centro Hospitalar e Universitário do Porto, Largo Prof. Abel Salazar, 40995001 Porto, Portugal;

josefina.sts@gmail.com

Accepted 29 May 2017 Published Online First 19 July 2017

\section{ABSTRACT}

Chronic kidney disease (CKD) is higher in elderly, but mortality outweighs the risk of end-stage renal disease (ESRD). Our aim was to identify prognostic markers for ESRD or death in elderly CKD, within a competing-risk analysis. This is a longitudinal study of consecutive newly referred patients with CKD ages 65 years, followed until the time of the first event (ESRD or death), using a competing-risk analysis. A modified Charlson Comorbidity Index (mCCl) was subdivided into subgroups (0-2, 3-4, $\geq 5$ ). Patients were followed for hospitalizations that occurred prior to the outcomes. Among 416 patients, age $76 \pm 8$ years, $52 \%$ male, median estimated glomerular filtration rate of $32 \mathrm{~mL} /$ min per $1.73 \mathrm{~m}^{2}, 50 \%$ had diabetes, and $67 \%$ cardiovascular disease. Over a median follow-up of 3.6 years, 36 patients progressed to ESRD $(8.7 \%)$ and 103 died (24.8\%). Older age (subdistribution $H R(s H R)=1.06 ; p<0.001)$, creatinine $\geq 1.6 \mathrm{mg} /$ $\mathrm{dL}(\mathrm{sHR}=2.03, p=0.004)$, hemoglobin $<11 \mathrm{~g} / \mathrm{dL}$ ( $s H R=1.91, p=0.003), m C C l$ score $\geq 5$ ( $s H R=3.01$, $p<0.001)$ and having one or more hospitalizations $(\mathrm{sHR}=1.73, \mathrm{p}<0.001)$ were associated with death before ESRD. The independent predictors for ESRD with competing risk of death were: lower age ( $s H R=0.94 ; p=0.009)$, creatinine $\geq 1.6 \mathrm{mg} /$ $\mathrm{dL}(\mathrm{sHR}=3.26, p=0.006)$, hemoglobin $<11 \mathrm{~g} / \mathrm{dL}$ ( $\mathrm{sHR}=2.15, p=0.027)$, peripheral vascular disease $(s H R=3.45, p=0.001)$ and having one or more hospitalizations $(\mathrm{sHR}=1.56, \mathrm{p}=0.031)$. Elderly referred patients with CKD are near threefold more likely to die than progress to ESRD. A competingrisk framework based on available clinical and laboratory data may discriminate between those outcomes and could be used as a decision-making tool.

\section{INTRODUCTION}

The world's population is aging, and by demographic projections, in 2050, about $32 \%$ of the Portuguese population is projected to be aged 65 and over, meaningfully above the European Union average of $25.7 \%$.

Parallel to this, the prevalence of chronic kidney disease (CKD) is rising worldwide, and the elderly represent the most rapidly growing segment of the end-stage renal disease (ESRD)

\section{Significance of this study}

What is already known about this subject?

- Prevalence of chronic kidney disease (CKD) is rising worldwide, and the elderly represent the most rapidly growing segment of the end-stage renal disease (ESRD) population requiring renal replacement therapy.

- Mortality, mainly from cardiovascular disease, outweighs the risk of progression to ESRD in older patients with CKD.

\section{What are the new findings?}

- Our study includes the rigorous exploration of the first Portuguese CKD cohort that included patients aged 65 years over, newly referred to nephrology.

- We demonstrated that peripheral vascular disease was an independent predictor for ESRD, but was not associated with increased pre-ESRD mortality.

- We implemented a competing risk framework for the statistical analysis to examine risk factors based on available clinical and laboratory data, for ESRD and differentiating them from those that increase mortality.

How might these results change the focus of research or clinical practice?

- Identifying predictors of death and ESRD within a competing-risk approach may allow us to use them as a decision-making tool, enabling more targeted therapeutic intervention, in elderly patients with CKD.
To cite: Santos J, Fonseca I, Malheiro J, et al. J Investig Med 2017;65:1041-1048 population requiring renal replacement therapy (RRT) in wealthier countries. ${ }^{23}$ Portugal has the highest unadjusted incidence and prevalence of ESRD among European countries ${ }^{4}$ and $67.7 \%$ of the incident dialysis patients, in 2015, were over 65 years with a mean age of prevalent patients of 66.7 years. ${ }^{5}$

Despite the growing number of older patients initiating dialysis, another problem stands out in this group: mortality, mainly from cardiovascular disease, outweighs the risk 
of progression to ESRD. ${ }^{67}$ One of the major challenges to clinicians caring for older patients with CKD is to identify each patient's risk for progressive CKD and likelihood for requiring RRT in relation to the competing risk of death. This may involve important clinical decisions, such as referrals and procedures for dialysis access placement or transplant decision or on the contrary the possibility to identify patients with higher comorbid conditions at high risk of early death for which conservative management may be the best option.

Our aim was to characterize elderly patients with CKD who were newly referred to our outpatient department to determine the independent predictors of ESRD or death through a competing-risk analysis. Furthermore, we sought to identify potential variables that may indicate a higher likelihood of death before ESRD or of attaining first ESRD status.

\section{METHODS}

\section{Study design and population}

This longitudinal retrospective study included consecutive patients aged $\geq 65$ years with CKD (non-dialyzed and non-transplanted), newly referred to our outpatient Nephrology department in Hospital de Santo António, CHUP, between January 1, 2012 and December 31, 2012, followed until the occurrence of the first event (ESRD or death) or until the end of the study (April 30, 2016). Hospital de Santo António is a tertiary-care hospital affiliated with the Abel Salazar Institute of Biomedical Sciences, University of Porto, which serves a diverse population of 500,000 inhabitants in the North region of country.

The study was performed in accordance with the Declaration of Helsinki and approved by the Institutional Review Board of CHP.

The diagnosis of CKD was done by the KDIGO 2012 criteria. ${ }^{8}$ ESRD was defined as the need for RRT initiation or transplantation.

Baseline data included gender, age, weight, height, body mass index (BMI), CKD stage, proteinuria level, medication use, and associated comorbid conditions, such as diabetes, dyslipidemia, hypertension, smoking status, and cardiovascular disease (coronary artery disease, peripheral artery disease, and cerebrovascular accident). Coronary artery disease was defined as a previous myocardial infarction, angina pectoris, coronary artery bypass grafting, or coronary stent implantation. Peripheral artery disease was defined as the presence of intermittent claudication or with the need of peripheral revascularization or amputation.

Glomerular filtration rate (GFR) was estimated using the Chronic Kidney Disease Epidemiology (CKD-EPI) 2009 creatinine equation. ${ }^{9}$ Etiological diagnosis of CKD was based on the patient's history, proteinuria, kidney ultrasound, and kidney biopsy, when available. Data blood and urine routine measurements were collected: hemoglobin, platelet, serum albumin, urea nitrogen, creatinine, sodium, potassium, bicarbonate, chloride, calcium, phosphorus, intact parathyroid hormone (PTH), glucose, hemoglobin A1c, uric acid, lipid profile, iron, unsaturated iron binding capacity, ferritin, urinary sediment, and urine protein-to-creatinine ratio in spot urine sample.
Cognitive status was evaluated and screened using the Mini Mental State Examination, ${ }^{10}$ and classified as cognitive impairment if the score was 23 or lower.

Functional dependency was defined as the requiring of assistance in the activities of daily living and classified as totally dependent, partially dependent, and autonomous.

A modified version of the Charlson Comorbidity Index (mCCI), ${ }^{11} 12$ that is, by excluding subject's age and presence or absence of kidney disease, was calculated to assess severity of comorbidities and subdivided into three subgroups (0-2, $3-4$, and $\geq 5$ ).

During the follow-up, number and reasons for hospitalizations were registered, all-cause hospitalization and cardiovascular-related hospitalization, defined as hospitalization secondary to cardiovascular events (coronary artery disease, congestive heart failure, stroke or transient ischemic attack, peripheral artery disease). The cause of death was categorized as cardiovascular (defined as death due to cardiac, cerebrovascular, atherosclerotic or other vascular causes), malignancy, infection, other, and unknown causes.

\section{Statistical analysis}

Baseline characteristics for the all sample and by primary outcomes of interest are presented as medians with IQRs for continuous non-normally distributed variables and as proportions for categorical variables. Subgroups were compared using the $\chi^{2}$ for categorical and Mann-Whitney test for continuous variables.

Unadjusted incidence rates for progression of ESRD (defined as renal failure requiring RRT or transplant) and all-cause mortality before any RRT (pre-ESRD death) were calculated per 100 person-years.

Hospitalization rate was calculated as the number of hospital admissions, divided by years at risk, expressed as hospitalizations per patient-year, using Poisson regression.

Survival analysis was performed and the two outcomes of interest were progression of ESRD and all-cause mortality before any RRT (pre-ESRD death). These two events were considered as competing risks. Patients without any of these outcomes were censored at the date of their last recorded visit or at the end of the study period.

Regression models taking competing risks into account were carried out to analyze the independent effect of covariates on each of two competing endpoints. This analysis was performed considering two types of hazards: cause-specific hazard and subdistribution hazard. Proportional cause-specific hazard regression models were performed using the standard Cox (cause-specific hazard regression model), censoring all patients without the event of interest. If a patient initiated dialysis, then the endpoint of mortality was censored. If a patient died, then the outcome of dialysis initiation was censored. An alternative model proposed by Fine and Gray ${ }^{13}$ was the approach used in the current study to model the subdistribution hazard.

An exploratory analysis was performed to examine the unadjusted effect of the potential predictors of ESRD progression and patient death by fitting univariable models. The cause-specific HR and the subdistribution HR for ESRD or for patient death before any RRT were then estimated in multivariable analyses. The covariates were selected on the basis of univariate analysis and because of their potential 
biological plausibility to predict progression of ESRD and/ or death.

The variables included in the univariate competing-risk model were baseline age, gender, baseline serum creatinine $(<1.6$ or $\geq 1.6 \mathrm{mg} / \mathrm{dL}$, the median value for this sample), serum hemoglobin $(<11$ or $\geq 11 \mathrm{~g} / \mathrm{dL}),{ }^{14}$ BMI $(<18.5,18.5-24.9,25-29.9$, or $\geq 30)$, estimated GFR (eGFR) (continuous or categorized as $<60$ or $\geq 60 \mathrm{~mL} /$ min), tobacco use (never, former, or current), dyslipidemia, hypertension, diabetes, coronary artery disease, peripheral vascular disease, cerebrovascular disease, number of antihypertensive drugs, referral from primary care versus another hospital appointment, CKD etiology (diabetes vs others), cognitive status, functional dependency, mCCI score at baseline, and the occurrence of hospitalizations during the follow-up period. For both outcomes, the occurrence of hospitalizations during the follow-up period was used as a time-varying covariate.

Statistical analyses were performed using SPSS V.22.0 and STATA V.13.0 software packages. A significance level of 0.05 was considered.

\section{RESULTS}

\section{Baseline characteristics}

Among 416 patients newly referred, 52\% were male, with a mean age of 76 years, and $36 \%$ of them aged 80 years or more. Their baseline characteristics are summarized in table 1.

Fifty per cent of the patients were referred by primary care physicians. At baseline, they had a median eGFR of $32 \mathrm{~mL} / \mathrm{min}$ per $1.73 \mathrm{~m}^{2}$. The most frequent etiologies of renal disease were ischemic nephropathy (38\%), diabetic nephropathy (25.5\%) and unknown causes (13.5\%).

Most of the patients were non-smokers (74\%) and 22\% were obese (BMI $\left.>30 \mathrm{~kg} / \mathrm{m}^{2}\right)$. About $50 \%$ were diabetic, and $96 \%$ presented hypertension, of which $50 \%$ were receiving more than two antihypertensive drugs, renin-angiotensin blockade in $33 \%$ of them; $63 \%$ of the patients had a systolic blood pressure $>130 \mathrm{~mm} \mathrm{Hg}$. Dyslipidemia was present in $85 \%$ of the patients, $60 \%$ were under lipid-lowering medication. An active or previous malignancy was present in $15 \%$ of the patients. Cardiovascular disease was present in $67 \%$ of the patients, including coronary artery disease in $25 \%$, peripheral vascular disease in $19 \%$ and cerebrovascular disease in $23 \%$ of the patients.

Regarding functional dependency, $5 \%$ of the patients were totally dependent and 38\% were partially dependent. Cognitive impairment was present in $11 \%$ of the patients.

Most patients had a hemoglobin level $\geq 11 \mathrm{~g} / \mathrm{dL}$ (71\%), with no iron deficiency (ferritin level $\geq 100 \mathrm{ng} / \mathrm{mL}$ : $75 \%$; transferrin saturation $\geq 20 \%$ : $62 \%$ ).

Intact PTH was elevated in $81 \%$ of the patients, despite good control of calcium-phosphorus levels.

\section{Follow-up and outcomes}

During a median follow-up of 3.6 years (min-max: 0.024.3 years), 36 patients progressed to ESRD (8.7\%) and 103 patients died (24.8\%) prior to ESRD, giving an ESRD rate of $2.7 / 100$ patient-years and a mortality rate of 7.8/100 patient-years, respectively. Figure 1 shows the cumulative incidences of events, considering competing risks.
The leading causes of death prior to ESRD were cardiovascular (35\%), infection (29\%), malignancy (21\%), other causes (8\%), and unknown (7\%).

Concerning the 36 patients who initiated RRT, all of them hemodialysis, 18 patients started treatment with an arteriovenous fistula and 18 patients with a venous catheter. It should be mentioned that eight patients of overall cohort $(1.9 \%)$ that underwent fistula died without receiving dialysis.

\section{Hospitalizations}

During the follow-up period, 222 patients (53\%) were hospitalized for any reason, with a global hospitalization rate of 0.38 per patient-year. Stratifying for the competing events, the hospitalization rate was 1.27 per patient-year in the patients with ESRD, and 1.06 hospitalizations per patient-year in the patients who died before ESRD.

Cardiovascular-related hospitalization accounted for almost $40 \%$ of the hospitalization events during the same period. The global cardiovascular hospitalization rate was 0.15 hospitalizations per patient-year, being 0.56 cardiovascular hospitalizations per patient-year in the patients with ESRD and 0.39 hospitalizations per patient-year in the patients who died before ESRD.

\section{Competing-risk analysis of death and ESRD}

The Cox proportional hazards model indicated that baseline younger age, creatinine higher than $1.6 \mathrm{mg} / \mathrm{dL}$, hemoglobin lower than $11 \mathrm{~g} / \mathrm{dL}$, peripheral vascular disease diagnosis, and the occurrence of one or more hospitalizations (all-cause hospitalizations) during the follow-up were associated with higher risk of ESRD (table 2). Diabetes mellitus (vs other CKD etiologies) and mCCI score at baseline were not associated with higher risk of ESRD.

Older age, creatinine higher than $1.6 \mathrm{mg} / \mathrm{dL}$, hemoglobin lower than $11 \mathrm{~g} / \mathrm{dL}, \mathrm{mCCI}$ score $\geq 5$, and the occurrence of hospitalizations during the follow-up were associated with death before ESRD.

Conversely, subhazard ratios estimated from competing-risk regression necessarily discriminated between endpoints. Significant risk factors for ESRD included younger age, creatinine higher than $1.6 \mathrm{mg} / \mathrm{dL}$, hemoglobin lower than $11 \mathrm{~g} / \mathrm{dL}$, peripheral vascular disease, and the occurrence of one or more hospitalizations during the follow-up (table 3).

Risk factors for pre-ESRD death included older age, creatinine higher than $1.6 \mathrm{mg} / \mathrm{dL}$, hemoglobin lower than $11 \mathrm{~g} / \mathrm{dL}$, mCCI score $\geq 5$, and the occurrence of one or more hospitalizations during the follow-up. By adjusting for these competing risks, we show that peripheral vascular disease increases the cumulative incidence of ESRD, but is not associated with increased pre-ESRD mortality. Similarly, a mCCI score $\geq 5$ increased the hazard for pre-ESRD death, but not for RRT initiation.

\section{DISCUSSION}

In our cohort, newly referred patients aged over 65 years with CKD were near threefold more likely to die than progress to ESRD. These results were consistent with those found in previous studies confirming that elderly CKD are 
Downloaded from http://jim.bmj.com/ on April 3, 2018 - Published by group.bmj.com

\section{Original research}

Table 1 Baseline clinical characteristics of patients divided by outcomes

\begin{tabular}{|c|c|c|c|c|c|}
\hline & Total, $n=416$ & $\begin{array}{l}\text { Alive without } \\
\text { ESRD, } n=277\end{array}$ & ESRD, $n=36$ & $\begin{array}{l}\text { Dead without } \\
\text { ESRD, } n=103\end{array}$ & $\mathrm{p}$ Value \\
\hline Age (years) & $71(71-83)$ & $76(70-82)$ & $74(71-80)$ & $81(75-86)$ & $0.017^{*}$ \\
\hline Age $\geq 80$ years, $n(\%)$ & $149(36)$ & $87(31)$ & $7(19)$ & $55(53)$ & $<0.001^{*}$ \\
\hline Male, $n(\%)$ & $218(52)$ & $139(50)$ & $21(58)$ & $58(56)$ & 0.430 \\
\hline eGFR EPI (mL/min/1.73 m²) & $32(23-42)$ & $33(25-44)$ & $24(16-38)$ & $28(22-34)$ & $<0.001^{*}$ \\
\hline \multicolumn{6}{|l|}{ CKD stage, $\mathrm{n}(\%)$} \\
\hline Stage 1 & $6(2.0)$ & $4(1.0)$ & $0(0.0)$ & $2(2.0)$ & \\
\hline Stage 2 & $34(8.0)$ & $30(11)$ & $1(3.0)$ & $2(2.0)$ & $0.004^{*}$ \\
\hline Stage 3a & $46(11)$ & $45(16)$ & $1(3.0)$ & $0(0.0)$ & \\
\hline Stage $3 b$ & $139(33)$ & $101(37)$ & $7(19)$ & $31(30)$ & \\
\hline Stage 4 & $158(38)$ & $88(32)$ & $11(31)$ & $59(57)$ & \\
\hline Stage 5 & $34(8.0)$ & $9(3.0)$ & $16(44)$ & $9(9.0)$ & \\
\hline \multicolumn{6}{|l|}{ Referral, $n(\%)$} \\
\hline Primary care & $206(50)$ & $123(44)$ & $21(58)$ & $50(49)$ & $0.013^{*}$ \\
\hline Hospital appointment & $194(47)$ & $148(53)$ & $14(39)$ & $44(43)$ & \\
\hline Other & $16(3.8)$ & $6(2.2)$ & $1(2.8)$ & $9(8.7)$ & \\
\hline \multicolumn{6}{|l|}{ Primary renal disease, $\mathrm{n}(\%)$} \\
\hline Ischemic nephropathy & $158(38)$ & $105(38)$ & $13(36)$ & $40(39)$ & \\
\hline Diabetic nephropathy & $106(26)$ & $63(23)$ & $15(42)$ & $28(27)$ & 0.222 \\
\hline Glomerulonephritis & $16(3.8)$ & $10(3.6)$ & $1(2.8)$ & $5(4.9)$ & \\
\hline Other/unknown & $136(33)$ & $99(36)$ & $7(19)$ & $30(29)$ & \\
\hline BMI $\left(\mathrm{kg} / \mathrm{m}^{2}\right)$ & $27(24-30)$ & $27(24-31)$ & $26(24-30)$ & $26(23-29)$ & 0.112 \\
\hline Cognitive impairment, n (\%) & $47(11.3)$ & $30(10.8)$ & $3(8.3)$ & $14(13.6)$ & 0.632 \\
\hline Totally dependent & $24(5.8)$ & $15(5.4)$ & $2(5.6)$ & $7(6.8)$ & \\
\hline Partially dependent & $156(38)$ & $96(35)$ & $17(47)$ & $43(42)$ & 0.430 \\
\hline Autonomous & $236(57)$ & $166(60)$ & $17(47)$ & $53(52)$ & \\
\hline \multicolumn{6}{|l|}{$\mathrm{mCCl}, \mathrm{n}(\%)$} \\
\hline $0-2$ & $184(44.2)$ & $148(53.4)$ & $12(33.3)$ & $24(23.3)$ & $<0.001^{*}$ \\
\hline $3-4$ & $127(30.5)$ & $84(30.3)$ & $12(33.3)$ & $31(30.1)$ & \\
\hline$>5$ & $105(25.2)$ & $45(16.2)$ & $12(33.3)$ & $48(46.6)$ & \\
\hline Diabetes, n (\%) & $207(50)$ & $133(48)$ & $52(61)$ & $49(51)$ & 0.330 \\
\hline $\begin{array}{l}\text { Former/current } \\
\text { smoking, } \mathrm{n}(\%)\end{array}$ & $110(27)$ & $66(24)$ & $11(31)$ & $33(32)$ & 0.246 \\
\hline $\mathrm{SBP}(\mathrm{mm} \mathrm{Hg})$ & $140(125-155)$ & $141(127-158)$ & $138(120-159)$ & $132(121-150)$ & $0.037^{*}$ \\
\hline $\mathrm{DBP}(\mathrm{mm} \mathrm{Hg})$ & $70(63-80)$ & $71(64-80)$ & $77(60-81)$ & $68(60-76)$ & $0.017^{*}$ \\
\hline Antihypertensive $\geq 2, \mathrm{n}(\%)$ & $207(50)$ & $140(51)$ & $18(50)$ & $49(48)$ & 0.876 \\
\hline $\begin{array}{l}\text { Renin-angiotensin } \\
\text { blockade }\end{array}$ & $137(33)$ & $88(32)$ & $16(44)$ & $33(32)$ & 0.306 \\
\hline Diuretics & $295(71)$ & $196(71)$ & $30(83)$ & $69(67)$ & 0.177 \\
\hline Dyslipidemia, n (\%) & $354(85)$ & $238(86)$ & $30(83)$ & $86(84)$ & 0.801 \\
\hline $\begin{array}{l}\text { Lipid-lowering medication, } \\
\mathrm{n}(\%)\end{array}$ & $248(60)$ & $168(61)$ & $22(61)$ & $58(56)$ & 0.712 \\
\hline $\begin{array}{l}\text { Antiplatelet medication, } \\
\mathrm{n}(\%)\end{array}$ & $203(49)$ & $135(39)$ & $14(52)$ & $54(49)$ & 0.376 \\
\hline $\begin{array}{l}\text { Cardiovascular diseases, } \\
\mathrm{n}(\%)\end{array}$ & $277(67)$ & $172(62)$ & $22(61)$ & $65(63)$ & 0.739 \\
\hline $\begin{array}{l}\text { Peripheral vascular disease, } \\
\mathrm{n}(\%)\end{array}$ & $78(19)$ & $43(16)$ & $15(42)$ & $20(19)$ & 0.001 \\
\hline Albumin <3.5 g/dL, n (\%) & $40(11)$ & $24(10)$ & $5(15)$ & $11(12)$ & 0.667 \\
\hline Uric acid (mg/dL) & $7.3(5.6-9.8)$ & $7.2(5.4-9.6)$ & $7.4(5.9-9.3)$ & $7.7(6.2-11.3)$ & 0.367 \\
\hline Total cholesterol (mg/dL) & $176(147-205)$ & $179(150-205)$ & $175(142-207)$ & $168(142-204)$ & 0.355 \\
\hline $\mathrm{HDL}(\mathrm{mg} / \mathrm{dL})$ & $47(38-57)$ & $48(39-57)$ & $48(36-59)$ & $45(37-58)$ & 0.720 \\
\hline LDL (mg/dL) & $98(75-123)$ & 99 (79-121) & $95(71-118)$ & $95(74-132)$ & 0.673 \\
\hline Hemoglobin (g/dL) & $11.9(10.6-13.6)$ & $12.0(10.9-13.4)$ & $11.3(10.6-13.1)$ & $11.6(10.1-13.1)$ & 0.086 \\
\hline TSAT (\%) & $21(14-28)$ & $21(15-28)$ & $21(15-33)$ & $21(14-28)$ & 0.642 \\
\hline Ferritin (ng/mL) & $160(80-337)$ & $150(77-344)$ & $151(70-256)$ & $181(90-363)$ & 0.407 \\
\hline
\end{tabular}


Table 1 Continued

\begin{tabular}{lllllr}
\hline & & Alive without & & Dead without \\
& Total, $\mathbf{n}=\mathbf{4 1 6}$ & ESRD, $\mathbf{n = 2 7 7}$ & ESRD, $\mathbf{n = 3 6}$ & ESRD, $\mathbf{n = 1 0 3}$ & $\mathrm{p}$ Value \\
\hline iPTH (pg/mL) & $100(61-155)$ & $98(61-161)$ & $115(69-140)$ & $99(61-156)$ & 0.446 \\
Calcium (mg/dL) & $2.4(2.3-2.5)$ & $2.4(2.3-2.5)$ & $2.4(2.3-2.5)$ & $2.3(2.2-2.5)$ & 0.158 \\
Phosphate (mg/dL) & $1.1(0.99-1.25)$ & $1.1(0.99-1.24)$ & $1.1(0.90-1.17)$ & $1.2(1.00-1.33)$ & 0.292 \\
uPCr (g/g) & $0.25(0.1-1.0)$ & $0.28(0.11-1.11)$ & $0.19(0.07-0.47)$ & $0.19(0.10-0.85)$ & 0.147 \\
\hline
\end{tabular}

Note: Data expressed as medians and IQRs or $\mathrm{n}(\%)$ when appropriate. Comparisons between continuous variables were done using a non-parametric test (KruskalWallis); associations between categorical variables were analyzed using the $\chi^{2}$ test; ${ }^{*} p<0.05$.

BMI, body mass index; CKD, chronic kidney disease; DBP, diastolic blood pressure; EGFR, estimated glomerular filtration rate; ESRD, end-stage renal disease; HDL, high density lipoprotein; $\mathrm{PTH}$, intact parathyroid hormone; LDL, low density lipoprotein; $\mathrm{mCCl}$, modified Charlson Comorbidity Index; SBP, systolic blood pressure; TSAT, transferrin saturation; $\mathrm{UPCr}$, urinary protein-to-creatinine ratio.

far less likely to develop kidney failure than to die, especially from cardiovascular disease, even with higher CKD stage. ${ }^{671516}$

However, our results differ from others, also from patients with CKD referred for nephrologist care, ${ }^{17} 18$ who have been showed to have either similar or even higher risk of ESRD compared with death. We can speculate about the reasons for these differences, namely our patients were older, with a higher burden of comorbidity and frailty. In fact, $25 \%$ of our patients have a severe mCCI score (CCI $\geq 5$ ), $43 \%$ have some degree of functional dependency and $11 \%$ had a cognitive impairment.

Our cohort fits the frailty phenotype associated with CKD and geriatric syndrome, ${ }^{19}{ }^{20}$ in contrast with other elderly CKD European cohorts newly referred to nephrologists, ${ }^{16}$ that despite older than our patients, had a good health status, reflecting a selection bias in referring patients for nephrology care, not found in our group.

To better understand the chances associated with the competing risks between mortality and ESRD, in elderly patients with CKD, where the supply of conservative management is weighed against the benefits and costs of RRT, we have applied a competing-risks mode $1^{13}$ that looks at the cumulative incidence of ESRD or death before ESRD while also taking into consideration competing risk of the alternate outcome. We believe that such approach better identifies prognostic factors for a particular event in the

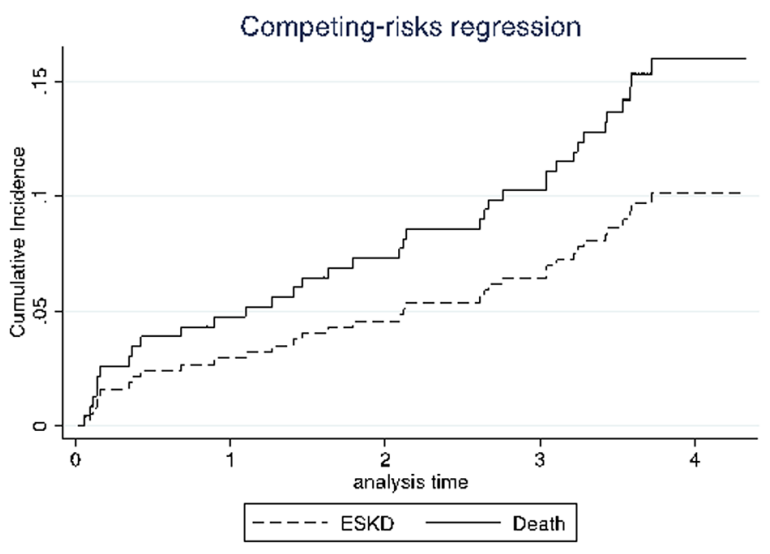

Figure 1 Cumulative incidence rates for the competing endpoints of end-stage renal disease or death. presence of competing risks and provide an important tool for better decision-making. ${ }^{21}$

In the competing-risk framework, patients who are younger, with creatinine higher than $1.6 \mathrm{mg} / \mathrm{dL}$, hemoglobin lower than $11 \mathrm{~g} / \mathrm{dL}$, had previous peripheral vascular disease and one or more hospitalizations during the follow-up, are more likely to reach ESRD. Those who are older, with creatinine higher than $1.6 \mathrm{mg} / \mathrm{dL}$, hemoglobin lower than $11 \mathrm{~g} / \mathrm{dL}$, mCCI score $\geq 5$ and one or more hospitalizations during the follow-up, are more likely to die.

Our findings confirm that renal function at baseline was an important predictor for both ESRD and mortality ${ }^{622-25}$ although this association was stronger for ESRD than for death, still reinforce the importance of early nephrology referral. In fact, in our cohort a shorter time between referral and ESRD was also associated with RRT initiation by catheter as primary access.

We found, as others, ${ }^{26}$ that anemia (hemoglobin $<11 \mathrm{~g} /$ dL) was a predictor of mortality and ESRD, undoubtedly related with adverse cardiovascular effects and the potential role of hypoxia on CKD progression, particularly important in this elderly population. This highlights the importance of anemia treatment although the target hemoglobin is still a matter of debate. ${ }^{1427}$

The occurrence of one or more hospitalizations was common in our cohort and it was associated with both outcomes (ESRD and death). The increased risk for mortality among patients with hospitalization is consistent with other studies, assuming that the majority of those hospitalizations were cardiovascular-related, ${ }^{28} 29$ or associated with an infection event, also known a risk factor for increased cardiovascular events and mortality in patients with CKD. ${ }^{30}$

The occurrence of hospitalizations events during the follow-up was also associated with ESRD. In our group the global and cardiovascular hospitalization rate was higher in patients with ESRD, than in the patients who died before RRT initiation. These findings are consistent with other studies, ${ }^{293132}$ as cardiovascular admissions may have served as a marker for patients who had more progressive ischemic nephropathy, or more important, related to a superimposed acute kidney injury (AKI) episode on the underlying CKD. ${ }^{29}{ }^{33}$ AKI episodes, frequent in elderly population, may accelerate progression of renal disease. ${ }^{3435}$

We demonstrated that peripheral vascular disease was an independent predictor for ESRD, but was not associated with increased pre-ESRD mortality. These findings extend 


\section{Original research}

Table 2 Risk factors associated with death and ESRD (Cox regression analysis)

\begin{tabular}{|c|c|c|c|c|}
\hline & \multicolumn{2}{|l|}{ ESRD } & \multicolumn{2}{|l|}{ Death } \\
\hline & $\operatorname{csHR}(95 \% \mathrm{Cl})$ & $\mathrm{p}$ Value & $\operatorname{csHR}(95 \% \mathrm{CI})$ & $\mathrm{p}$ Value \\
\hline \multicolumn{5}{|l|}{ Baseline } \\
\hline Age, years & 0.95 (0.91 to 1.00$)$ & 0.049 & 1.04 (1.01 to 1.07$)$ & 0.004 \\
\hline Creatinine ( $>1.6 \mathrm{vs}<1.6 \mathrm{mg} / \mathrm{dL}$ ) & 3.64 (1.58 to 8.38$)$ & 0.002 & 2.27 (1.44 to 3.57 ) & $<0.001$ \\
\hline $\mathrm{Hb}(<11.0 \mathrm{vs}>11.0 \mathrm{~g} / \mathrm{dL})$ & $2.72(1.35$ to 5.49$)$ & 0.005 & 2.20 (1.49 to 3.26$)$ & $<0.001$ \\
\hline \multicolumn{5}{|l|}{$\mathrm{CCl}$ score } \\
\hline (3-4 vs $1-2$ ) & 0.55 (0.22 to 1.39$)$ & 0.205 & 1.35 (0.80 to 2.29$)$ & 0.258 \\
\hline$(\geq 5$ vs $1-2)$ & $0.80(0.33$ to 1.96$)$ & 0.626 & 2.82 (1.70 to 4.67$)$ & $<0.001$ \\
\hline $\begin{array}{l}\text { Peripheral vascular disease } \\
\text { (yes vs no) }\end{array}$ & $3.60(1.70$ to 7.60$)$ & 0.001 & 1.03 (0.64 to 1.68$)$ & 0.890 \\
\hline DM vs other CKD etiologies & 1.75 (0.85 to 3.58$)$ & 0.127 & 1.02 (0.67 to 1.55$)$ & 0.930 \\
\hline \multicolumn{5}{|l|}{ During the follow-up } \\
\hline Hospitalizations (yes vs no) & 1.72 (1.17 to 2.52$)$ & 0.006 & 1.84 (1.44 to 2.36$)$ & $<0.001$ \\
\hline
\end{tabular}

Note: Values given as cSHR ( $95 \% \mathrm{Cl})$ for risk factors associated with ESRD and death prior to ESRD.

CCI, Charlson Comorbidity Index; CKD, chronic kidney disease; csHR, cause-specific HR; DM, diabetes mellitus; ESRD, end-stage renal disease; Hb, hemoglobin.

the association between vascular disease and CKD progression founded in other studies, ${ }^{31} 3637$ given that peripheral vascular disease is the result of an atherosclerotic process similar to that one seen in cardiovascular disease. As we know, atherosclerosis is a potentially important mechanism of kidney disease in older persons ${ }^{38} 39$ and increases the susceptibility for AKI and CKD progression. ${ }^{40} \mathrm{~A}$ study in European cohort, ${ }^{41}$ also using a competing risks modeling approach, showed that the endogenous inhibitor of nitric oxide synthase, asymmetric dimethylarginine, considered one of the strongest markers of atherosclerosis, was an independent predictor of progression to dialysis and death in patients with CKD.

A reduced ankle-brachial index reflects peripheral arterial disease, and some studies demonstrated that this atherosclerotic disease marker predicted accelerated renal function decline, in general population, ${ }^{42}$ and also in peritoneal dialysis patients. ${ }^{43}$

Given that finding, our study suggests that the presence of peripheral arterial disease, although reflecting an atherosclerotic systemic process also involving the kidneys, may be a potential marker for renal function decline in patients with CKD, through other mechanisms, in addition to the traditional association of CKD with vascular damage.

The higher burden of CV risk factors, and prevalent vascular disease, present in our cohort, and the association between peripheral vascular disease and ESRD that we found, may partially explain the highest incidence of ESRD of Portuguese population among European countries, ${ }^{4}$ because data from the PREVADIAB Study ${ }^{44}$ have shown that the prevalence of CKD stages 3-5 was $6.1 \%$, which is similar to that in other Western countries. The reasons for this disparity are still a matter of debate. Although socioeconomic and political factors still play a part in RRT rates around the world, other important factors are genetics, birth weight, dietary habits, and diabetes prevalence. Another important issue is the age pattern at beginning of RRT. In countries with lower RRT incidence, the median age at start of RRT appears to be lower, suggesting that countries with higher RRT incidence, like Portugal, start older patients in RRT and this may contribute to differences in RRT epidemiology between countries. ${ }^{45}$ In this respect, there is an urgent need for concrete evidence on the relative benefit of conservative treatment versus RRT

Table 3 Risk factors associated with death and ESRD (Fine and Gray model ${ }^{13}$ )

\begin{tabular}{|c|c|c|c|c|}
\hline & \multicolumn{2}{|l|}{ ESRD } & \multicolumn{2}{|l|}{ Death } \\
\hline & sHR $(95 \% \mathrm{Cl})$ & $\mathrm{p}$ Value & sHR $(95 \% \mathrm{Cl})$ & $\mathrm{p}$ Value \\
\hline \multicolumn{5}{|l|}{ Baseline } \\
\hline Age, years & 0.94 (0.89 to 0.98$)$ & 0.009 & 1.06 (1.03 to 1.09$)$ & $<0.001$ \\
\hline Creatinine (>1.6vs <1.6 mg/dL) & 3.26 (1.40 to 7.60$)$ & 0.006 & 2.03 (1.25 to 3.29$)$ & 0.004 \\
\hline Peripheral vascular disease (yes vs no) & 3.45 (1.68 to 7.10$)$ & 0.001 & 0.82 (0.49 to 1.34$)$ & 0.435 \\
\hline \multicolumn{5}{|l|}{$\mathrm{CCl}$ score } \\
\hline (3-4 vs 1-2) & $0.57(0.24$ to 1.35$)$ & 0.202 & 1.53 (0.87 to 2.69$)$ & 0.137 \\
\hline$(\geq 5$ vs $1-2)$ & 0.54 (0.23 to 1.28$)$ & 0.164 & $3.01(1.75$ to 5.19$)$ & $<0.001$ \\
\hline $\mathrm{Hb}(<11.0 \mathrm{vs}>11.0 \mathrm{~g} / \mathrm{dL})$ & 2.15 (1.09 to 4.24$)$ & 0.027 & 1.91 (1.25 to 2.92$)$ & 0.003 \\
\hline DM vs other CKD etiologies & $1.72(0.84$ to 3.53$)$ & 0.139 & 0.84 (0.54 to 1.32$)$ & 0.447 \\
\hline \multicolumn{5}{|l|}{ During the follow-up } \\
\hline Hospitalizations (yes vs no) & 1.56 (1.04 to 2.35$)$ & 0.031 & 1.73 (1.33 to 2.25$)$ & $<0.001$ \\
\hline
\end{tabular}

Note: Values given as sHR $(95 \% \mathrm{Cl})$ for risk factors associated with ESRD and death prior to ESRD.

CCl, Charlson Comorbidity Index; CKD, chronic kidney disease; DM, diabetes mellitus; ESRD, end-stage renal disease.; Hb, hemoglobin; sHR, subdistribution HR. 
in the elderly as well as on the optimal timing of RRT initiation.

Finally, we found that mCCI score $\geq 5$ was an independent predictor for pre-ESRD death, but not for RRT initiation. The CCI has been widely used and validated in patients with ESRD and seemed to be significantly more predictive for mortality than other comorbidity scoring systems $^{46} 47$ This is evidenced by studies demonstrating that elderly patients with CKD are likely to have a higher burden of comorbidity and frailty, which are markers of worst survival. ${ }^{46}$

Old age alone should not be used as an absolute barrier to treatment when considering the benefits of dialysis in elderly patients with CKD. ${ }^{48}$ However, in the elderly patients with CKD with a high burden of comorbidity, conservative management may be a therapeutic option, as dialysis is unlikely to prolong or improve quality of life. ${ }^{49-51}$

Also, considering the likelihood of death prior to ESRD makes preparation for RRT, as the placement of an arteriovenous access unnecessary and potentially harmful. ${ }^{52}$

The strengths of our study include the rigorous exploration of the first Portuguese CKD cohort that included patients aged 65 years over, newly referred to nephrology, reflecting current clinical practice. We implemented a competing-risk framework for the statistical analysis to examine risk factors based on available clinical and laboratory data, for ESRD and differentiating them from those that increase mortality, which is an important tool to guide clinical decision process.

The effect of peripheral vascular disease as an independent predictor for ESRD in our cohort, although it deserves more research, reinforces the importance of strategic targeting vascular risk screening and reduction in this population.

There are certain limitations to our research. First, this is a single-center retrospective study. Second, due to the overall small number of patients who initiated RRT $(n=36)$, it is not possible to identify the risk factors for progression within each CKD stage. In the stages 3 and 4, only 8 and 11 patients progressed to dialysis, respectively. Thus, we do not have sufficient number of events for performing a reliable survival analysis using mortality as a competing event.

Third, defining ESRD as the RRT initiation has the disadvantage of being dependent on local clinical practice. Fourth, proteinuria could not be included in the multivariable models due to the percentage of missings and, therefore, we could not analyze the effect of proteinuria on the risk of ESRD or death. Finally, because this cohort only comprised patients attending nephrology outpatient clinic, which can introduce a bias of referral, the results may not be generalizable to a non-referred population.

\section{CONCLUSION}

In summary, we found that newly referred older patients with CKD are substantially more likely to die than to reach ESRD. By using a competing-risk approach based on available clinical and laboratory data, we could identify risk factors predictors of CKD progression and distinguishing them from those that increase mortality, which may allow us to use them as a decision-making tool to guide clinical decision process.
Contributors JS, IF and JM were involved in research design, writing and in data collection. IB, LL, PO and AC were involved in editing.

Competing interests None declared.

Ethics approval The study was performed in accordance with the Declaration of Helsinki and approved by the Institutional Review Board of Centro Hospitalar Universitário do Porto.

Provenance and peer review Not commissioned; externally peer reviewed.

(c) American Federation for Medical Research (unless otherwise stated in the text of the article) 2017. All rights reserved. No commercial use is permitted unless otherwise expressly granted.

\section{REFERENCES}

1 OECD and EU. A good life in Old Age?: monitoring and improving Quality in Long-term care, OECD Health Policy Studies. Paris: OECD Publishing, 2013.

2 Saran R, Li Y, Robinson B, et al. US Renal Data System 2014 Annual data Report: epidemiology of Kidney Disease in the United States. Am J Kidney Dis 2015;66:A7-S306.

3 Pippias M, Stel VS, Abad Diez JM, et al. Renal replacement therapy in Europe: a summary of the 2012 ERA-EDTA Registry Annual Report. Clin Kidney J 2015;8:248-61.

4 Kramer A, Pippias M, Stel VS, et al. Renal replacement therapy in Europe: a summary of the 2013 ERA-EDTA Registry Annual Report with a focus on diabetes mellitus. Clin Kidney J 2016;9:457-69.

5 Macário F. Gabinete De Registo Da Sociedade Portuguesa Nefrologia. http:// www.spnefro.pt/comissoesgabinetes/Gabinete_registo2015/registo_2015. pdf

6 O'Hare AM, Choi Al, Bertenthal D, et al. Age affects outcomes in chronic kidney disease. J Am Soc Nephrol 2007;18:2758-65.

7 Dalrymple LS, Katz R, Kestenbaum B, et al. Chronic kidney disease and the risk of end-stage renal disease versus death. J Gen Intern Med 2011;26:379-85.

8 Kidney Disease: Improving Global Outcomes (KDIGO) CKD Work Group. KDIGO clinical practice guideline for the evaluation and management of chronic kidney disease. Kidney Int 2013;3:1-150.

9 Levey SA, Stevens LA, Schmid CH, et al. CKD-EPI (Chronic kidney disease Epidemiology Collaboration). A new equation to estimate glomerular filtration rate. Ann Intern Med 2009;150:604-12.

10 Folstein MF, Folstein SE, McHugh PR. "Mini-mental state". A practical method for grading the cognitive state of patients for the clinician. J Psychiatr Res 1975;12:196-8.

11 Charlson ME, Pompei P, Ales KL, et al. A new method of classifying prognostic comorbidity in longitudinal studies: development and validation. J Chronic Dis 1987;40:373-83.

12 Rattanasompattikul M, Feroze U, Molnar MZ, et al. Charlson comorbidity score is a strong predictor of mortality in hemodialysis patients. Int Urol Nephrol 2012;44:1813-23.

13 Fine JP, Gray RJ. A proportional hazards Model for the subdistribution of a competing risk. J Am Stat Assoc 1999;94:496-509.

14 Locatelli F, Aljama P, Bárány P, et al. Revised European best practice guidelines for the management of anaemia in patients with chronic renal failure. Nephrol Dial Transplant 2004;19 Suppl 2:ii1-47.

15 Demoulin N, Beguin C, Labriola L, et al. Preparing renal replacement therapy in stage 4 CKD patients referred to nephrologists: a difficult balance between futility and insufficiency. A cohort study of 386 patients followed in Brussels. Nephrol Dial Transplant 2011;26:220-6.

16 Faller B, Beuscart JB, Frimat L, et al. Competing-risk analysis of death and dialysis initiation among elderly ( $\geq 80$ years) newly referred to nephrologists: a French prospective study. BMC Nephrol 2013;14:103-14.

17 Agarwal R, Bunaye Z, Bekele DM, et al. Competing risk factor analysis of end-stage renal disease and mortality in chronic kidney disease. Am J Nephrol 2008;28:569-75.

18 Levin A, Djurdjev 0, Beaulieu M, et al. Variability and risk factors for kidney disease progression and death following attainment of stage 4 CKD in a referred cohort. Am J Kidney Dis 2008;52:661-71.

19 Shlipak MG, Stehman-Breen C, Fried LF, et al. The presence of frailty in elderly persons with chronic renal insufficiency. Am J Kidney Dis 2004;43:861-7.

20 Roshanravan B, Khatri M, Robinson-Cohen C, et al. A prospective study of frailty in nephrology-referred patients with CKD. Am J Kidney Dis 2012;60:912-21.

$21 \mathrm{Kim}$ HT. Cumulative incidence in competing risks data and competing risks regression analysis. Clin Cancer Res 2007;13:559-65.

22 Landray MJ, Emberson JR, Blackwell L, et al. Prediction of ESRD and death among people with CKD: the chronic renal impairment in Birmingham (CRIB) prospective cohort study. Am J Kidney Dis 2010;56:1082-94. 
23 Foley RN, Murray AM, Li S, et al. Chronic kidney disease and the risk for cardiovascular disease, renal replacement, and death in the United States Medicare population, 1998 to 1999. J Am Soc Nephrol 2005;16:489-95.

24 Coresh J, Turin TC, Matsushita K, et al. Decline in estimated glomerular filtration rate and subsequent risk of end-stage renal disease and mortality. JAMA 2014;311:2518-31

25 Hallan SI, Matsushita K, Sang Y, et al. Chronic kidney disease Prognosis Consortium. Age and association of kidney measures with mortality and endstage renal disease. JAMA 2012;308:2349-60.

26 Thorp ML, Johnson ES, Yang X, et al. Effect of anaemia on mortality, cardiovascular hospitalizations and end-stage renal disease among patients with chronic kidney disease. Nephrology 2009;14:240-6.

27 Mimura I, Tanaka T, Nangaku M. How the Target Hemoglobin of Renal Anemia Should Be. Nephron 2015;131:202-9.

28 Lee DS, Austin PC, Stukel TA, et al. Dose-dependent impact of recurrent cardiac events on mortality in patients with heart failure. Am J Med 2009;122:162. e1-162.e9.

29 Sud M, Tangri N, Pintilie M, et al. Risk of end-stage renal disease and death after cardiovascular events in chronic kidney disease. Circulation 2014;130:458-65.

30 Cheikh Hassan HI, Tang M, Djurdjev 0, et al. Infection in advanced chronic kidney disease leads to increased risk of cardiovascular events, end-stage kidney disease and mortality. Kidney Int 2016;90:897-904.

31 Elsayed EF, Tighiouart H, Griffith J, et al. Cardiovascular disease and subsequent kidney disease. Arch Intern Med 2007;167:1130-6.

32 Kalra PA, Guo H, Kausz AT, et al. Atherosclerotic renovascular disease in United States patients aged 67 years or older: risk factors, revascularization, and prognosis. Kidney Int 2005;68:293-301.

33 Johnson ES, Smith DH, Thorp ML, et al. Predicting the risk of end-stage renal disease in the population-based setting: a retrospective case-control study. BMC Nephrol 2011;12:17-24.

34 Ishani A, Xue JL, Himmelfarb J, et al. Acute kidney injury increases risk of ESRD among elderly. J Am Soc Nephrol 2009;20:223-8.

35 Schmitt R, Coca S, Kanbay M, et al. Recovery of kidney function after acute kidney injury in the elderly: a systematic review and meta-analysis. Am J Kidney Dis 2008:52:262-71.

36 Shlipak MG, Katz R, Kestenbaum B, et al. Clinical and subclinical cardiovascular disease and kidney function decline in the elderly. Atherosclerosis 2009;204:298-303

37 Kuo TH, Yang DC, Lin WH, et al. Compliance Index, a Marker of Periphera Arterial Stiffness, may Predict Renal Function Decline in Patients with Chronic Kidney Disease. Int J Med Sci 2015:12:530-7.
38 Kasiske BL. Relationship between vascular disease and age-associated changes in the human kidney. Kidney Int 1987;31:1153-9.

39 Bleyer AJ, Shemanski LR, Burke GL, et al. Tobacco, hypertension, and vascular disease: risk factors for renal functional decline in an older population. Kidney Int 2000:57:2072-9.

40 Mittalhenkle A, Stehman-Breen CO, Shlipak MG, et al. Cardiovascular risk factors and incident acute renal failure in older adults: the cardiovascular health study. Clin J Am Soc Nephrol 2008;3:450-6.

41 Ravani P, Tripepi G, Malberti F, et al. Asymmetrical dimethylarginine predicts progression to Dialysis and death in patients with chronic kidney disease: a competing risks modeling approach. J Am Soc Nephrol 2005;16:2449-55.

42 Foster MC, Ghuman N, Hwang SJ, et al. Low ankle-brachial index and the development of rapid estimated GFR decline and CKD. Am J Kidney Dis 2013;61:204-10.

43 Tian SL, Tian XK, Han QF, et al. Presence of peripheral arterial disease predicts loss of residual renal function in incident CAPD patients. Perit Dial Int 2012;32:67-72

44 Vinhas J, Gardete-Correia L, Boavida JM, et al. Prevalence of chronic kidney disease and associated risk factors, and risk of end-stage renal disease: data from the PREVADIAB study. Nephron Clin Pract 2011;119:c35-c40.

45 Gonzalez-Espinoza L, Ortiz A. 2012 ERA-EDTA Registry Annual Report: cautious optimism on outcomes, concern about Persistent inequalities and data blackouts. Clin Kidney J 20152015;8:243-7.

46 Pugh J, Aggett J, Goodland A, et al. Frailty and comorbidity are independent predictors of outcome in patients referred for pre-dialysis education. Clin Kidney J 2016;9:324-9.

47 van Manen JG, Korevaar JC, Dekker FW, et al. How to adjust for comorbidity in survival studies in ESRD patients: a comparison of different indices. Am J Kidney Dis 2002;40:82-9.

48 Jassal SV, Trpeski L, Zhu N, et al. Changes in survival among elderly patients initiating Dialysis from 1990 to 1999. CMAJ 2007;177:1033-8.

49 Chandna SM, Da Silva-Gane M, Marshall C, et al. Survival of elderly patients with stage 5 CKD: comparison of conservative management and renal replacement therapy. Nephrol Dial Transplant 2011;26:1608-14.

50 Kurella Tamura M, Covinsky KE, Chertow GM, et al. Functional status of elderly adults before and after initiation of Dialysis. N Engl J Med 2009;361:1539-47.

51 Carson RC, Juszczak M, Davenport A, et al. Is maximum conservative management an equivalent treatment option to Dialysis for elderly patients with significant comorbid disease? Clin J Am Soc Nephrol 2009;4:1611-9.

52 O'Hare AM, Bertenthal D, Walter LC, et al. When to refer patients with chronic kidney disease for vascular access surgery: should age be a consideration? Kidney Int 2007:71:555-61. 

a Portuguese cohort of elderly patients: an approach using competing event analysis

Josefina Santos, Isabel Fonseca, Jorge Malheiro, Idalina Beirao, Luisa Lobato, Pedro Oliveira and Antonio Cabrita

J Investig Med2017 65: 1041-1048 originally published online July 19, 2017

doi: $10.1136 / \mathrm{jim}-2017-000480$

Updated information and services can be found at:

http://jim.bmj.com/content/65/7/1041

These include:

References This article cites 50 articles, 10 of which you can access for free at:

http://jim.bmj.com/content/65/7/1041\#ref-list-1

Email alerting

Receive free email alerts when new articles cite this article. Sign service up in the box at the top right corner of the online article.

\section{Notes}

To request permissions go to:

http://group.bmj.com/group/rights-licensing/permissions

To order reprints go to:

http://journals.bmj.com/cgi/reprintform

To subscribe to BMJ go to:

http://group.bmj.com/subscribe/ 